\title{
Utilidad del suero autólogo en lesiones de superficie ocular de evolución incierta. Evaluación clínica e imagenológica
}

Borobio E 1,a; Hernández-Patiño I*2,3,b; Rossani G 2,3,b; López E ${ }^{1 a}$;Talavera E 2,3,d; Johny de la Cruz V 2,c

\section{RESUMEN}

Objetivo: Determinar la efectividad del suero autólogo rico en factores de crecimiento en la reparación de lesiones de la superficie ocular de evolución incierta con el tratamiento convencional.

Materiales y métodos: Se trataron 46 unidades oculares con afecciones de la superficie ocular agrupadas en queratopatías por exposición, queratopatías por síndrome de ojo seco / neurotróficas, y traumas oculares. Las partes oculares afectadas fueron: conjuntiva, cornea (epitelio, estroma) y esclera. Se evaluaron de manera anatómica y funcional con la prueba de Schirmer, tinción con Fluoresceína y tomografía de coherencia óptica (TCO) entre marzo y diciembre del 2020.

Resultados: Los síntomas mejoraron en el siguiente orden: dolor ocular, sensación de cuerpo extraño, blefaroespasmo, hiperemia y lagrimeo. Las lesiones evolucionaron favorablemente de la siguiente manera: en primer lugar las conjuntivales y del epitelio corneal, luego las del estroma corneal y finalmente las lesiones en la esclera. Se obtuvo una media de 15 días para recuperación inmediata de la superficie y de 21 días para recuperación tardía. Las lesiones con adelgazamiento parcial profundo de esclera tomaron alrededor de 2 meses.

Conclusiones: Los hallazgos relacionados al umbral del dolor, tiempo de recuperación, remodelación cicatrizal del tejido afectado y recuperación de la agudeza visual son prometedores e importantes. La utilización de suero autólogo rico en factores de crecimiento puede ser una alternativa terapéutica para las lesiones de difícil resolución con el tratamiento convencional.

Palabras clave: Suero; Factores de crecimiento; Plasma rico en plaquetas; Lesiones oculares (Fuente: DeCS BIREME).

\section{Usefulness of autologous serum for ocular surface lesions with uncertain progression. A clinical and imaging evaluation}

\section{ABSTRACT}

Objective: To determine the effectiveness of autologous serum rich in growth factors to repair ocular surface lesions which have uncertain progression with conventional treatment.

Materials and methods: AForty-six (46) eyes with ocular surface disorders such as exposure keratopathy, keratopathy caused by dry eye syndrome, neurotrophic keratopathy and blunt eye injury were treated. The affected areas were the conjunctiva, cornea (epithelium, stroma) and sclera. Anatomical and functional evaluations were performed between March and December 2020 using Schirmer's test, fluorescein eye stain and optical coherence tomography (OCT).

Results: The symptoms improved in the following order: eye pain, foreign body sensation, blepharospasm, hyperemia and epiphora. Additionally, the lesions progressed favorably as follows: first, those of the conjunctiva and corneal epithelium; then, those of the corneal stroma; and, finally, those of the sclera. An average of 15 days was required for immediate ocular surface recovery and 21 days for late recovery. The lesions with total scleral thinning healed in about two months.

Conclusions: The findings related to pain threshold, recovery time, scar tissue remodeling of the affected tissue and visual acuity improvement are promising and important. Using autologous serum rich in growth factors may be a therapeutic alternative for those lesions that are difficult to resolve with conventional treatment.

Keywords: Serum; Intercellular signaling peptides and proteins; Platelet-rich plasma; Eye injuries (Source: MeSH NLM).

1 Oftalmología Avanzada S.R.L. Lima, Perú.

2 Universidad Ricardo Palma, Facultad de Medicina, Instituto de Investigación en Ciencias Biomédicas. Lima, Perú.

3 Instituto Peruano de Ingeniería Celular y Manufactura Tisular A.C.INGECEL. Lima, Perú.

a Médico Oftalmólogo.

b Médico Cirujano Plástico, Magíster.

c Médico Oncólogo, Doctor en Medicina.

d Estudiante de Medicina.

* Autor corresponsal. 


\section{INTRODUCCIÓN}

La mala cicatrización de las lesiones de la superficie ocular es una de las principales causas de deterioro visual $y$, en algunos casos, de ceguera ${ }^{(1,2)}$. Estas afecciones pueden ser muy simples y de fácil resolución, pero también presentan secuelas graves que son difíciles de manejar ${ }^{(2)}$. Los pacientes pueden verse afectados de por vida, lo que debilitaría la economía familiar y el sistema de salud. Además, el tratamiento habitual no siempre tiene un resultado favorable. Por ello, es necesario encontrar nuevas terapias que ayuden a la recuperación del paciente ${ }^{(3)}$.

La cicatrización errática de la córnea es una de las causas más frecuentes de ceguera y pérdida de la visión. Se estima que alrededor de 500000 lesiones oculares ocasionan ceguera, de las cuales el trauma es la causa unilateral principal en todo el mundo (2). Estas lesiones son más frecuentes en adultos jóvenes (20 a 40 años) que forman parte de la población económica productiva ${ }^{(4)}$. Esto se evidencia ya que las dos terceras partes de las lesiones ocurren en el trabajo a causa de una escasa conciencia sobre protección ocular. El resto se debe a accidentes domésticos ${ }^{(5)}$.

Estas urgencias representan un porcentaje importante de todos los eventos atendidos en los servicios de emergencia: en un hospital en España son el $6 \%{ }^{(6)}$; en Francia, un $5 \%{ }^{(7)}$; en Gran Bretaña, el $6 \%{ }^{(8)}$; y en Estados Unidos ${ }^{(9)}$, un $8 \%$ del total. Las lesiones producidas por álcalis son dos veces más frecuentes que las provocadas por ácidos, debido a que los primeros son productos de uso frecuente en el hogar y las industrias ${ }^{(10)}$.

Las lesiones oculares están en el primer lugar en los cuadros de partes del cuerpo lesionadas con un $10,02 \%$, como reporta el Boletín del anuario estadístico mensual de notificaciones de accidentes de trabajo, incidentes peligrosos y enfermedades ocupacionales del Ministerio del Trabajo y Promoción del Empleo del Perú en junio del $2020{ }^{~(11) . ~ A s i m i s m o, ~ s e g u ́ n ~ e l ~ D e p a r t a m e n t o ~ d e ~ E s t a d i ́ s t i c a ~}$ del Instituto Nacional de Oftalmología (INO), hasta el tercer trimestre del año 2019, las lesiones oculares que afectaron la córnea bordearon los 12700 casos, por lo que ocupan el tercer lugar, en frecuencia, de las atenciones ${ }^{(12)}$.

Ahora bien, las lesiones que afectan la superficie ocular pueden ser mecánicas (con erosiones o úlceras), químicas (por ácido o cáusticos), térmicas o físicas, como la queratitis actínica, y las producidas por enfermedades autoinmunes o crónicas, como la neurotrófica ${ }^{(13)}$.

En el caso de la úlcera corneal, algunos microorganismos suelen invadir la superficie lesionada y producen un tejido infiltrativo en la región afectada (14), lo que provoca una pérdida de sustancia, dolor, trastorno de la agudeza visual, fotofobia, blefaroespamo y lagrimeos.

La córnea es uno de los tejidos más nobles en cuanto a la reparación: una lesión simple puede sanar en unas pocas horas y un daño más serio puede tomar unos pocos días. La reparación del estrato superficial es completa y no tendría por qué evolucionar con opacificación corneal. Sin embargo, a pesar de esta capacidad regenerativa, la evolución puede cambiar su curso, facilitar la aparición de infecciones de la córnea y producir mayores procesos inflamatorios ${ }^{(9)}$.

El endotelio corneal que es la capa más profunda de esta tiene una extraordinaria importancia desde el punto de vista de intercambio y potencial de membrana cuya finalidad es el transporte de sustancias iónicamente activas y mantener el equilibrio hídrico del epitelio, manteniendo así la integridad y propiedad más importante de la córnea que es la transparencia. Esta bomba endotelial depende de oxígeno, glucosa y ATPasa que genera una diferencia de potencial eléctrico en la membrana. Las drogas utilizadas como medicinas modifican este potencial, ayudando o empeorando los casos de regeneración de tejidos ${ }^{(15)}$.

En oftalmología, los factores de crecimiento plaquetarios se utilizan para el tratamiento del ojo seco sintomático, las úlceras corneales, las quemaduras oculares, entre otras aplicaciones, y son una alternativa eficaz en diversas enfermedades oculares ${ }^{(16)}$.

Varios factores de crecimiento plaquetarios están envueltos en el mantenimiento de la estructura y la función de la córnea, especialmente en relación con la conservación de la transparencia durante el proceso de reparación. La ventaja de utilizar el suero enriquecido en factores de crecimiento, en lugar del suero común, es que el primero contiene una mayor concentración de vitaminas, citoquinas, leucocitos y factores de crecimiento. El suero de plaquetas intactas funciona también como una membrana biológica y mecánica ${ }^{(17)}$. Además, el suero autólogo rico en factores de crecimiento contiene inmunoglobulinas, lisozimas y factores complementarios que proporcionan efectos bactericidas y bacteriostáticos; su composición, pH y osmolaridad son similares en un $99 \%$ a los componentes de la lágrima (18).

El acceso de las sustancias bioactivas que ayudan en la reparación tisular inmediata desde los vasos sanguíneos (como vía de administración) hasta la zona lesionada es difícil debido a las alteraciones que provoca una lesión traumática o inflamatoria en el tejido de la superficie ocular.

La evidencia científica demuestra que los factores de crecimiento mejoran la cicatrización con epitelios 
muy parecidos a los originales. Por ello, pretendemos demostrar que el suero autólogo rico en factores de crecimiento utilizado en las lesiones de la superficie ocular de desenlace incierto puede mejorar las condiciones de recuperación, ya que fomenta una mejor cicatrización con un tejido resultante idóneo en menor tiempo, disminuye las complicaciones infecciosas de estas lesiones, mejora la visión y logra la satisfacción por los resultados en los participantes del estudio, además de disminuir los costos hospitalarios y socio-sanitarios.

\section{MATERIALES Y MÉTODOS}

\section{Diseño y población de estudio}

Estudio clínico cuasiexperimental y cualicuantitativo. Se reclutaron a pacientes con diagnóstico de lesiones de la superficie ocular agudas o lesiones crónicas que no se han resuelto con el tratamiento habitual de trauma ocular, queratitis neurotrófica y queratopatía por exposición, que acudieron al Centro de Oftalmología Avanzada S. R. L. durante el periodo de marzo a diciembre del 2020. El muestreo fue probabilístico y aleatorio simple. Las 46 unidades tratadas se obtuvieron de 29 pacientes incluidos en el estudio (de un total de 53 seleccionados). Veinticuatro pacientes fueron excluidos por no cumplir los criterios de inclusión.

\section{Variables y mediciones}

Se buscó el efecto reparador del suero autólogo rico en factores de crecimiento (variable dependeicnete), sobre los factores que pueden influir en esta (variables independeicnetes), etiología de la lesión, edad y sexo del paciente, número de días de tratamiento para la recuperación, signos y síntomas del paciente. Para ello, se confeccionó y validó una ficha clínica en la que el equipo de Oftalmología registró los datos (prueba de Schirmer, tinción de fluoresceína y tomografías oculares) y los reportes clínicos de la evolución. Se conformaron dos equipos de trabajo: el primero estuvo a cargo de un médico oftalmólogo, y se encargó de la evaluación, selección y control de los pacientes, según el diagnóstico. El segundo equipo fue dirigido por el Instituto Peruano de Ingeniería Celular y Manufactura de Tejidos, y se encargó de la toma de muestra de sangre, de la preparación y adecuación del suero autólogo rico en factores de crecimiento. Este suero se aplicó en forma gotas oftálmicas cada 6 horas por 15 días de manera asistida, ambulatoria y sistemática. En algunos casos, la sesión se repitió de acuerdo con el origen, el tiempo y la profundidad de la lesión. El tratamiento, control y evolución de los pacientes fue realizada por elmismo equipo médico y se evaluó el progreso de las lesiones a partir del tercer día después de la aplicación.

Se tomó una muestra de $20 \mathrm{~cm}^{3}$ de sangre periférica que se añadió a tubos de laboratorio estériles de $3,5 \mathrm{~cm}^{3}$ con citrato de sodio al 3,2\%. Luego se centrifugó a 3500 r. p. m. por 8 minutos. Para el gotero utilizamos frascos estériles de $20 \mathrm{~cm}^{3}$. Después de la centrifugación, obtuvimos entre 6 a $8 \mathrm{ml}$ (120 a 160 gotas) de suero autólogo rico en factores de crecimiento (8 gotas por día/ojo por 10 días). El suero autólogo fue rotulado y debidamente almacenado por no más de 15 días a $4{ }^{\circ} \mathrm{C}$, tiempo en el cual las proteínas empiezan a desnaturalizarse. Una vez obtenido el suero autólogo, lo colocamos en un frasco gotero estéril sellado para su posterior manipulación por el paciente, a quien se indica la manera de utilizarlo. Su uso proporcionará un efecto de barrera y hará las veces de membrana biológica.

Inmediatamente después de aplicar las gotas, el paciente debe manter los ojos cerrados durante 8 a 10 minutos luego de cada aplicación: esto favorecerá la acción de las lágrimas sobre el suero autólogo rico en plaquetas y liberará su contenido proteico. Esto suele ocurrir en los primeros 8 a 12 minutos. Los controles se realizaron cada 72 horas; luego de este periodo, la efectividad se evaluó de acuerdo a las variables mencionadas. Las sesiones para manufactura de gotas oftálmicas de suero autólogo se repitieron cada 15 días hasta lograr una satisfactoria reepitelización o recuperación del tejido afectado en cada paciente.

\section{Análisis estadístico}

Los estudios que se realizaron fueron estadísticos descriptivos y cualitativos.

\section{Consideraciones éticas}

Los pacientes que decidieron participar de manera voluntaria lo expresaron de manera verbal y por escrito e ingresaron al estudio luego de firmar el Protocolo de Consentimiento Informado.

\section{RESULTADOS}

De 29 pacientes (13 hombres y 16 mujeres), obtuvimos 46 unidades oculares con diferentes enfermedades. El rango de edad fue de 50 a 80 años (Figura 1). 
Borobio E; Hernández-Patiño I; Rossani G; López E; Talavera E; Johny de la Cruz V

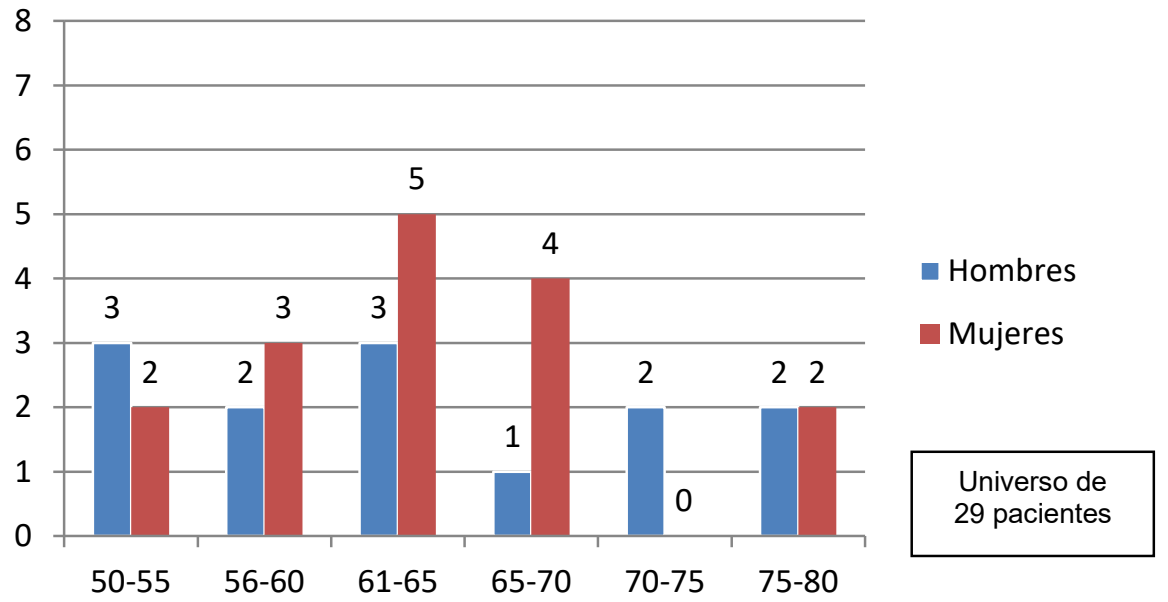

Figura 1. Número de pacientes incluidos distribuidos por grupo etáreo y sexo

De las 46 unidades oculares, 27 presentaban queratopatía por Sd. de ojo seco / neurotróficas; 6 unidades por queratopatía por exposición y 13 unidades oculares por trauma ocular (Figura 2).

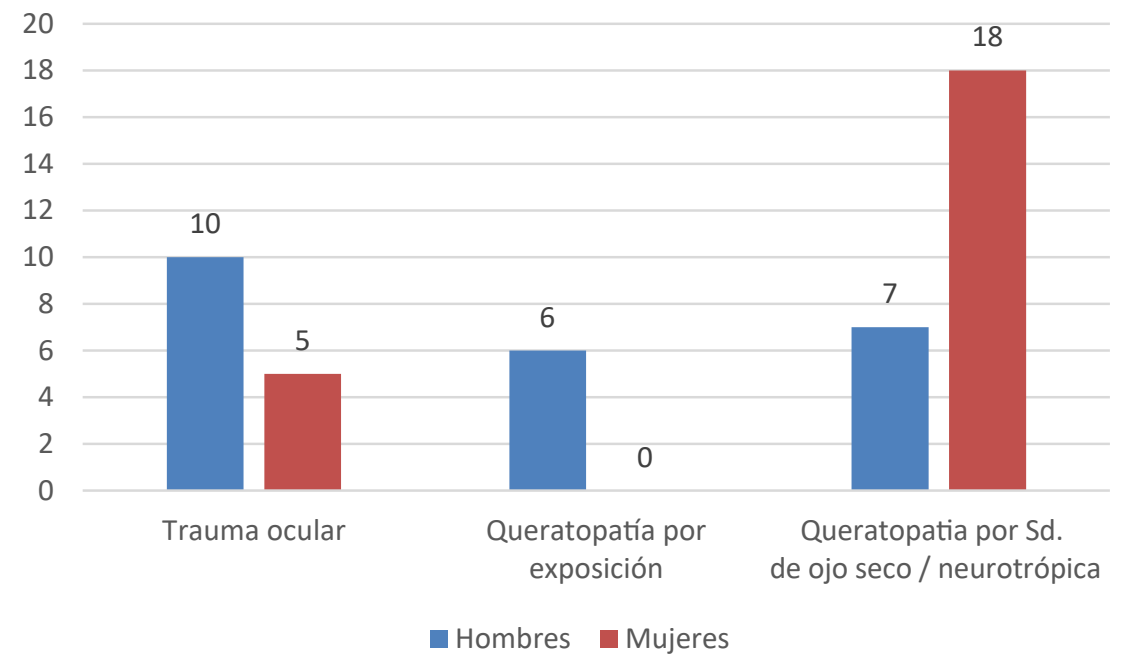

Figura 2. Unidades oculares tratadas distribuidas por sexo y enfermedad

En la tabla 1 en el grupo de las queratopatías por síndrome de ojo seco y neurotróficas (27 unidades): 18 con síndrome de ojo seco sin otra patología ocular asociada, 2 cursaban con úlcera corneal, 2 con glaucoma, 2 con queratitis filamentosa y 3 con queratitis neurotróficas por herpes virus. En el grupo de las queratopatías por exposición se trataron seis unidades oculares de queratitis actínica (todas en hombres). En el grupo de traumas oculares se trataron 13 unidades: 2 fueron debido a úlceras corneales post resección de pterigión, 1 por dellen escleral profundo (exposición a rayos beta), 8 con úlceras corneales por trauma ocular directo, 2 con úlceras corneales por quemadura por ácido (batería de automóvil). (Ver tabla $\mathrm{N}^{\circ} 1$ ). 
Utilidad del suero autólogo en lesiones de superficie ocular de evolución incierta.

Evaluación clínica e imagenológica

Tabla 1. Unidades oculares tratadas distribuidas por sexo y etiología

\begin{tabular}{|lccc|}
\hline \multicolumn{1}{|c}{ Enfermedades } & Hombres & Mujeres & Total \\
\hline Úlcera corneal posresección de pterigión & 0 & 2 & 2 \\
\hline Úlcera escleral por rayos beta & 1 & 0 & 1 \\
\hline Úlcera corneal por trauma ocular & 6 & 2 & 8 \\
\hline Úlcera corneal por ácido de batería & 2 & 0 & 2 \\
\hline Queratitis filamentosa & 1 & 1 & 2 \\
\hline Queratitis actínica & 6 & 0 & 6 \\
\hline Ojo seco & 6 & 12 & 18 \\
\hline Ojo seco-glaucoma & 0 & 2 & 2 \\
\hline Ojo seco-úlcera corneal & 0 & 2 & 2 \\
\hline Herpes ocular & 1 & 2 & 3 \\
\hline Total & 23 & 23 & 46 \\
\hline
\end{tabular}

Las queratopatías por exposición requirieron menos sesiones para lograr tanto disminuir la sintomatología como la pronta recuperación de la superficie ocular, recibiendo en promedio 1 sesión. Las queratopatías por sd. de ojo seco / neurotróficas requirieron en promedio 1,5 sesiones para lograr los objetivos. Finalmente, las lesiones producidas por trauma ocular requirieron más sesiones con una media de 2,8 para regenerar la superficie.

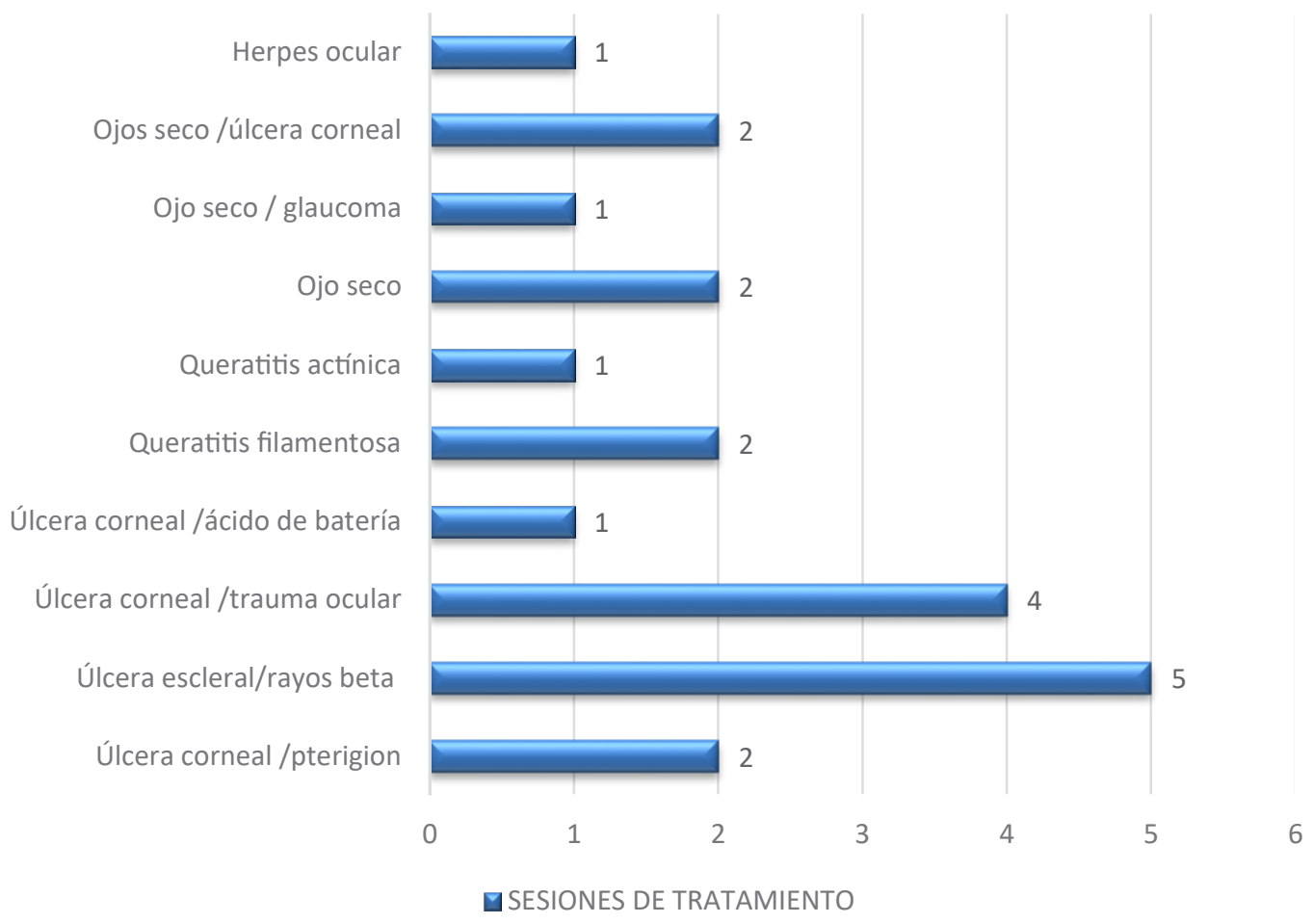

Figura 3. Sesiones por etiología 
Borobio E; Hernández-Patiño I; Rossani G; López E; Talavera E; Johny de la Cruz V

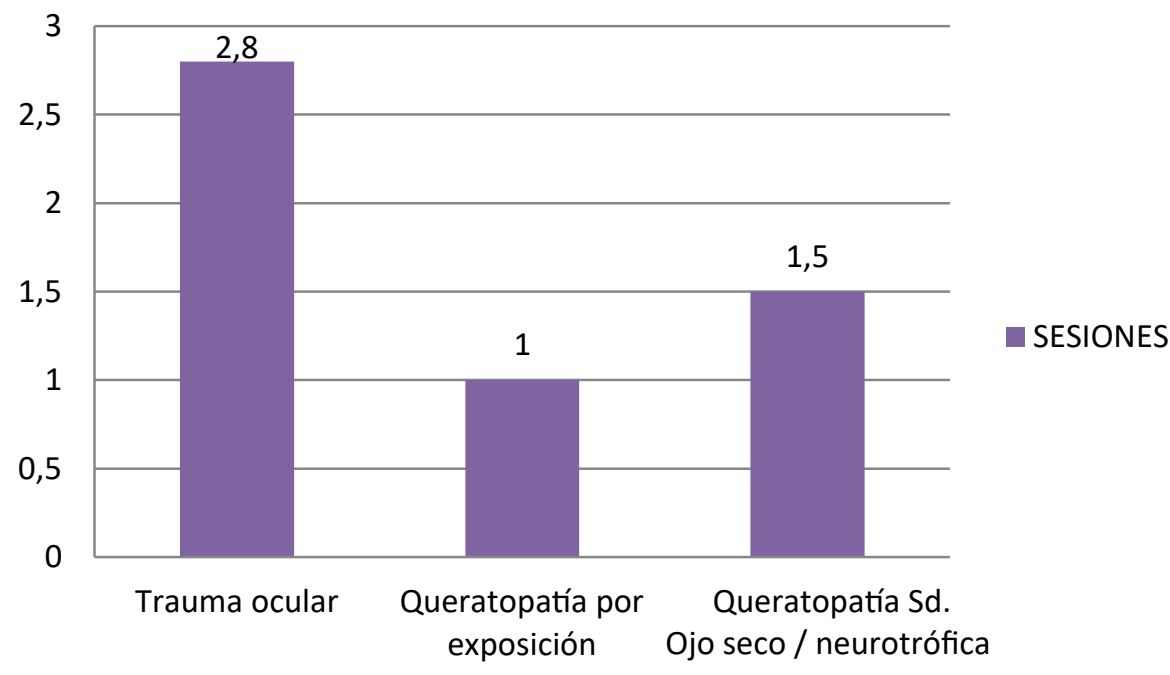

Figura 4. Media de sesiones de tratamiento por grupo de enfermedad

Dentro de la sintomatología propia de estas patologías, el grupo que respondió más rápido fueron las queratopatías por exposición, el dolor fue el primer síntoma en mejorar con una media de 1,3 días. La sensación de cuerpo extraño, el blefaroespasmo y la hiperemia conjuntival, mejoraron en dos días en promedio. El lagrimeo ocupo el tercer lugar con 2,33 días en promedio. Finalmente la fotofobia con una media de tres días. (Ver Figura $\mathrm{N}^{\circ} 5$ )

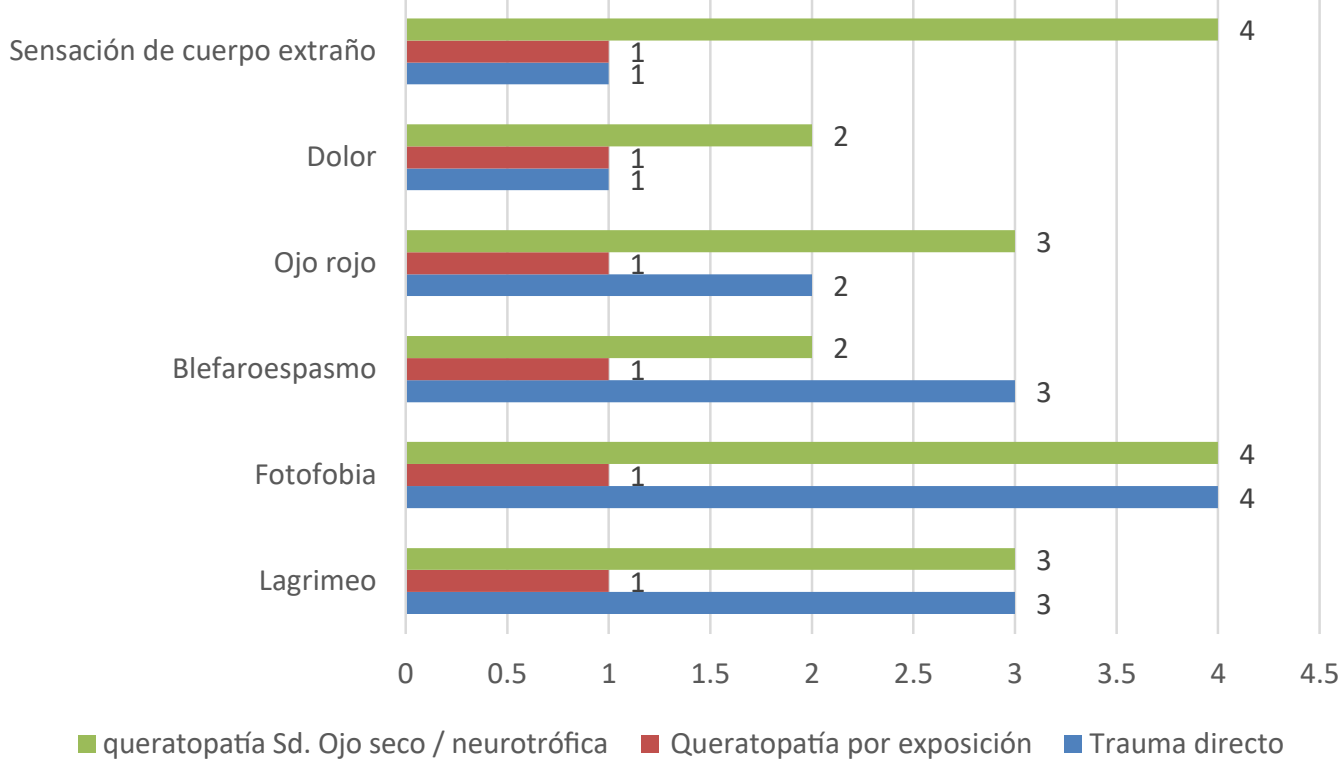

Figura 5. Días para evidenciar mejoras en la sintomatología, según grupo de enfermedad

En el estudio de la superficie ocular, las lesiones del epitelio corneal evolucionaron más rápido (Figura 6); en segundo lugar, el estroma corneal, y por último, las lesiones de la esclera (exposición a los rayos beta que adelgazaron la esclera casi hasta perforarla). El rango promedio para la recuperación de la superficie inmediata estuvo en 15 días; mientras que tiempo de recuperación tardía fue 21 días, en relación directa con la profundidad y extensión de la lesión, e independientemente de la edad, del tiempo de evolución y del tipo de lesión. Las lesiones que comprometían la 
esclera a consecuencia de la aplicación de rayos beta y/o por trauma ocular directo (postcirugía de pterígion) con adelgazamiento total de la esclera tomaron más tiempo para la regeneración total: 45 y 60 días, respectivamente (Figura 6,7,y 8).

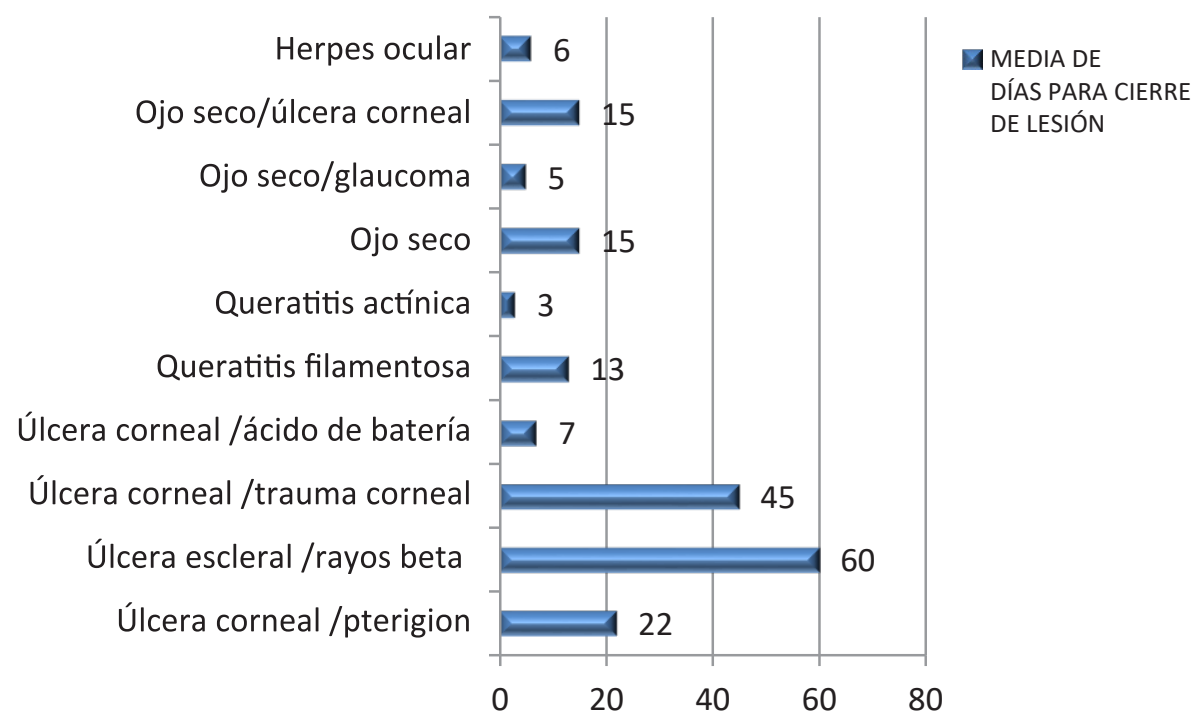

Figura 6. Número de días para regeneración de las lesiones de la superficie ocular, según naturaleza.

Las imágenes de la evolución de algunas lesiones por OCT (Fig. 7 y 8 )

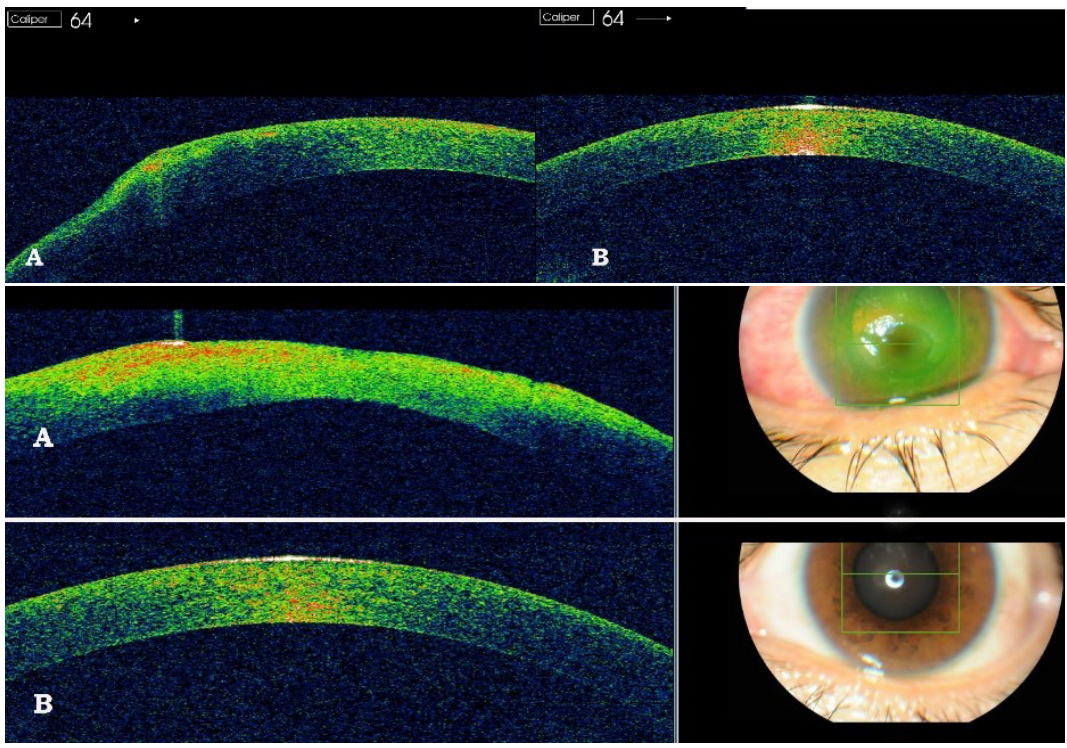

Figura 7. A. Úlcera corneal con dellen escleral por trauma quirúrgico (resección de pterigion) B. Después del tratamiento con suero autólogo. 


\section{DISCUSIÓN}

Las tres fases de reparación tisular involucran moléculas bioactivas que se encuentran en la sangre periférica. Las plaquetas son medulares en la reparación de las heridas ${ }^{(19)}$. Montón-Echevarria et al. ${ }^{(20)}$ concluyen que la utilización de los factores de crecimiento acelera la reparación de tejidos blandos y óseos con evidente disminución del dolor, las infecciones y el tiempo postoperatorio.

Esto se explica porque los factores de crecimiento son útiles y eficaces para determinadas enfermedades oftalmológicas en las que la terapéutica actual es limitada, como las úlceras corneales, el síndrome de ojo seco, el síndrome post-LASIK, la perforación ocular, la disfunción de la glándula lagrimal, los agujeros maculares y los trasplantes de limbo (21).

Las evidentes mejoras en el dolor, la fotofobia, el blefaroespamo, el lagrimeo, la visión y los resultados anatómicos favorables medidos con TAC ocular, aun con una muestra pequeña, justifican este procedimiento también en los pacientes que no mejoran con la terapia habitual. En España, Víctor García J. et. al.(22) indican que, debido a la satisfacción de los pacientes y de los oftalmólogos, este es un tratamiento que va a seguir prescribiéndose mientras la ciencia no recomiende otro más efectivo o menos molesto para el paciente.

En nuestro estudio no observamos complicaciones derivadas del uso del suero autólogo, situación que también describen otros autores ${ }^{(23)}$.

Luego de atender a 46 unidades oftalmológicas, concluimos que la aplicación asistida de gotas oftálmicas de suero autólogo en lesiones de la superficie ocular de evolución lenta e incierta en el tratamiento convencional acorta el tiempo de recuperación al inducir la cicatrización, mejorar la calidad del tejido resultante, aliviar los síntomas, disminuir el tiempo de tratamiento, y conlleva a una alta satisfacción de los pacientes por los resultados obtenidos. Además, disminuyen los costos de las terapias y los pacientes se reincorporan más pronto al trabajo, lo que reduce las carga familiar y sanitaria estatal.

Por lo tanto, debido a nuestros resultados y a los obtenidos por otros autores, este tratamiento con suero autólogo sería una alternativa terapéutica útil y eficiente de la especialidad.

Debido a la muestra limitada, es evidente la importancia de realizar nuevos estudios con mayor potencial para seguir demostrando la efectividad de este producto autólogo, atóxico, no inmunogénico y de bajo costo, el cual podría considerarse como un tratamiento altamente reproducible al tratarse de un procedimiento relativamente fácil, de bajo costo y fácil acceso para el paciente y el médico tratante.

Contribuciones de los autores: Los autores participaron en la generación, redacción y aprobación final del artículo original, así como en la recolección de datos.

Conflicto de interés: Los autores manifiestan no tener ningún conflicto de interés.

Fuentes de financiamiento: Este artículo fue financiado por un Grant (ACU 2738-2019 / 0243-2020) otorgado por la Facultad de Medicina, por medio de la oficina de Vicerrectorado de Investigación de la Universidad Ricardo Palma. Lima, Perú.

\section{REFERENCIA BIBLIOGRÁFICAS}

1. López-García JS, García-Lozano I, Rivas L, Martínez-Garchitorena J. Use of autologous serum in ophthalmic practice. Arch Soc Esp Oftalmol. 2007; 82(1): 9-20.

2. Geerling G, MacLennan S, Hartwig D. Autologous serum eye drops for ocular surface disorders. Br J Ophthalmol. 2004; 88(11): 1467-74.

3. León-Hernández FA, Taboada Esteve JF. Traumatismos Oculares graves en España: factores epidemiológicos, estudio de las lesiones y medidas de prevención. Barcelona; 1994. p. 12-27.

4. Ministerio de Salud. Guía Clínica: Trauma ocular grave [Internet]. MINSAL: Santiago; 2009. Disponible en: http://www.bibliotecaminsal. cl/wp/wp-content/uploads/2016/04/Trauma-Ocular-Grave.pdf

5. Díaz-Mendoza JJ, Chirinos-Saldaña MP, Uribe-Villarreal J, Hilario-Vargas J, Adrianzén RE. Características epidemiológicas de los traumatismos oculares en un instituto oftalmológico de referencia regional, Trujillo Perú, 2016-2017. Acta Med Perú. 2019; 36(4): 281-6.

6. Sánchez Tocino H, Galindo Ferreiro A, Iglesias Cortiñas D, Galindo Alonso J, Fernández Muñoz M. Estudio epidemiológico de las urgencias oftalmológicas en un hospital general. Arch Soc Esp Oftalmol. 2004; 79(9): 425-32.

7. Ameloot F. Activité et épidémiologie d'une unité d'urgence ophtalmologique récemment crééé au Centre Hospitalier Universitaire de Nancy. Université de Lorraine; 2012.

8. Edwards RS. Ophthalmic emergencies in a district general hospital casualty department. Br J Ophthalmol. 1987; 71(12): 938-42.

9. Nash EA, Margo CE. Patterns of emergency department visits for disorders of the eye and ocular adnexa. Arch Ophthalmol. 1998; 116(9): 1222-6.

10. Kanski JJ, Ofatlmología Clínica. 5ta ed. Barcelona: Elsevier; 2008. p. 689-91.

11. Ministerio de Trabajo y Promoción del Empleo. Notificaciones de accidentes de trabajo, incidentes peligrosos y enfermedades ocupacionales - Edición junio 2020 [Internet]. MTPE: Lima; 2020. Disponible en: https://www.gob.pe/institucion/mtpe/informespublicaciones / 1090070-boletin-estadistico-mensual-notificacionesde-accidentes-de-trabajo-incidentes-peligrosos-y-enfermedadesocupacionales-edicion-junio-2020

12. Instituto Nacional de Oftalmología. Departamento Estadística del Instituto Nacional de Oftalmología [Internet]. INO: Lima. Disponible en: https://www.ino.gob.pe/estadistica/

13. Ramos T, Scott D, Ahmad S. An update on ocular surface epithelial stem cells: cornea and conjunctiva. Stem Cells Int. 2015.

14. Harguindey S, Reshkin SJ, Orive G, Arranz JL, Anitua E. Growth and 
trophic factors, $\mathrm{pH}$ and the $\mathrm{Na}+\mathrm{H}+$ exchanger in Alzheimer's disease, other neurodegenerative diseases and cancer: new therapeutic possibilities and potential dangers. Curr Alzheimer Res. 2007; 4(1): 53-65.

15. Grayson M. Enfermedades de la córnea. Bogotá: Médica Panamericana; 1985.

16. Rezende Ribeiro MVM, Falcao de Melo V, Calado Barbosa MEF, de Franca Tozzi MU, Baracho Ramos MS, Soares Gaia NMSR, et al. The use of platelet rich-plasma in Ophthalmology: a literature review. Rev Bras Oftalmol. 2017; 76(6): 319-24.

17. Imanishi J, Kamiyama K, Iguchi I, Kita M, Sotozono C, Kinoshita S. Growth factors: importance in wound healing and maintenance of transparency of the cornea. Prog Retin Eye Res. 2000; 19(1): 113-29.

18. Urzua C, Vasquez DH, Huidobro A, Hernandez H, Alfaro J. Randomized double-blind clinical trial of autologous serum versus artificial tears in dry eye syndrome. Curr Eye Res. 2012; 37(8): 684-8.

19. Borzini P, Mazzucco I. Platelet-rich plasma (PRP) and platelet derivatives for topical therapy. What is true from the biological view point?. ISBT Science Series. 2007; 2(1): 272-81.

20. Montón-Echevarría J, Pérez Redondo S, Gómez Bajo GJ. Experiencia clínica en el empleo de factores de crecimiento autólogos obtenidos de plasma rico en plaquetas. Cir Plást Iberolatinoam. 2007; 33(3): $155-62$.

21. Solans Pérez de Larraya $A M$, Salgado Miranda AD, Ortega Molina JM, Chaves Samaniego MJ. Plasma enriquecido en plaquetas: una alternativa como tratamiento de la patología oftalmológica. Annals d'oftalmologia. 2015.

22. García Jiménez V, Veiga Villaverde B, Baamonde Arbaiza B, Carpintero IC, Celemín Viñuela ML, Simó Martínez RM. Elaboración, utilización y evaluación de un colirio con suero autólogo en las lesiones corneales. Farmacia hospitalaria. 2003; 27(1): 21-5.

23. Márquez De Aracena Del Cid R, Montero-Espinoza I, Pereira Gutiérrez G, Martín Leal F. Subconjunctival and topic treatment of plasma platelet concentrate in limbal transplantion. Mapfre Medicina. 2006; 17(4): 280-5.

\section{Correspondencia:}

Rafael Iván Hernández Patiño

Dirección: Av. Javier Prado este 414. San Isidro. Lima, Perú. Teléfono: +51999351542

Correo electrónico: ivan.hernandez@urp.edu.pe/centrocamelias@ gmail.com

Recibido: 22 de febrero de 2021

Evaluado: 23 de abril de 2021

Aprobado: 03 de mayo de 2021

(c) La revista. Publicado por Universidad de San Martín de Porres, Perú. (c) By Licencia de Creative Commons Artículo en acceso abierto bajo términos de Licencia Creative Commons Atribución 4.0 Internacional. (http://creativecommons.org/licenses/by/4.0/)

\section{ORCID iDs}

Borobio E

Ivan Hernández Patiño

German Rossani Alatrista

Jesús Enrique Talavera

Enriqueta López

Jhony De La Cruz Vargas

\footnotetext{
(D) https: / / orcid.org/0000-0001-9784-3714

(1) https: / / orcid.org/0000-0002-5654-1194

(D) https: / / orcid.org/0000-0002-9405-4821

(C) https: / / orcid.org/0000-0002-0267-2105

(D) https: / / orcid.org/0000-0002-6460-1353

(D) https: / / orcid.org/0000-0002-5592-0504
} 